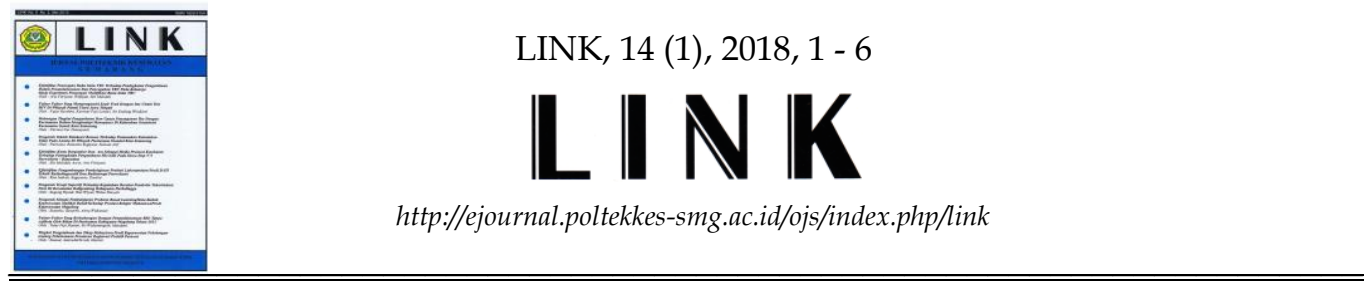

\title{
PEMBENTUKAN KELOMPOK PENDAMPING IBU HAMIL DI DESA KARANGGINTUNG KECAMATAN SUMBANG KABUPATEN BANYUMAS
}

\author{
Diki Retno Yuliani*) ; Ulfah Musdalifah ; Affi Zakiyya ; Fitria Zuhriyatun \\ Jurusan Kebidanan Purwokerto ; Poltekkes Kemenkes Semarang \\ Jl. Tirto Agung ; Pedalangan; Banyumanik; Semarang
}

\begin{abstract}
Abstrak
Dalam mensukseskan program “jateng gayeng nginceng wong meteng (5 NG)", pengabdi membuat kelompok pendamping ibu hamil didesa karanggintung, kecamatan sumbang, kabupaten banyumas. Tujuan kegiatan adalah terbentuk kelompok pendamping ibu hamil, untuk meningkatkan pencatatan, deteksi dini faktor resiko dan tanda bahaya ibu hamil sampai masa nifas dan neonatus. Sasaran kegiatan adalah kader kesehatan dan kader PKK sebagai calon pendamping. Kegiatan pembentukan kelompok pendamping meliputi penunjukan calon pendamping, pemaparan materi dan demonstrasi cara pendataan ibu hamil, membangun komitmen bersama, evaluasi tahap awal serta evaluasi tahap akhir. Hasil yang diperoleh adalah terbentuknya kelompok pendamping ibu hamil yang berkomitmen menjadi pendamping secara sukarela. Temuan di lapangan yang sesuai dengan kepustakaan adalah peran serta kader PKK dalam pendampingan ibu hamil. Sedangkan temuan yang tidak sesuai dengan kepustakaan adalah HPHT belum dikaji, trimester I tidak melakukan ANC dan hamil pada usia > 35 tahun. Kesimpulan dan saran adalah kelompok pendamping ibu hamil di Desa Karanggintung sudah mulai berjalan, namun diperlukan banyak perbaikan agar dapat berfungsi secara maksimal.
\end{abstract}

Kata kunci: Kelompok Pendampingan ; Ibu Hamil ; Kader ; Jateng

\begin{abstract}
[FORMATION A PREGNANT WOMEN MENTOR GROUP IN THE KARANGGINTUNG VILLAGE OF SUMBANG DISTRICT OF BANYUMAS REGENCY] Making the program successful "jateng gayeng nginceng wong meteng (5 NG) (5 NG)", the devotees make a companion group of pregnant women in villages karanggintung, sub-key, Banyumas regency. Its objective is to form a companion group of pregnant women, to increase the recording, early detection of risk factors and signs of danger to pregnant women during childbirth and neonates. Target activity is health cadres and cadres of the PKK as a potential companion. Event formation of advocacy groups includes the appointment of a candidate companion, exposure of the material and a demonstration of how data collection on maternal, build commitment, evaluation of the initial stage and the final stage of evaluation. The result is the formation of advocacy groups in pregnant women who are committed to becoming a companion voluntarily. The findings in the field according to the literature is the role of the PKK cadres in caring for pregnant women. While the findings do not correspond with the literature is HPHT not yet be assessed, the first trimester did ANC and pregnant at the age of $>35$ years. Conclusions and suggestions are a group of pregnant women in the village companion Karanggintung already underway, but needed a lot of improvement in order to function optimally.
\end{abstract}

Keywords: Assistance Group ; Pregnant ; Cadre ; Central Java

\section{Pendahuluan}

Pengabdian kepada masyarakat adalah kegiatan civitas akademika yang memanfaatkan

*) Diki Retno Yuliani

E-mail: dikiretnoyuliani@gmail.com ilmu pengetahuan dan teknologi untuk memajukan kesejahteraan masyarakat serta mencerdaskan kehidupan bangsa (UU Pendidikan Tinggi No. 12 Tahun 2012). 
Pengabdian Kepada Masyarakat di Politeknik Kesehatan Kemenkes Semarang adalah kegiatan civitas akademika dengan cara memanfaatkan potensi yang ada di Politeknik Kesehatan Kemenkes Semarang sebagai kontribusi dalam mewujudkan masyarakat yang sehat dan berkeadilan. Prodi DIII Kebidanan Purwokerto Jurusan Kebidanan Poltekkes Kemenkes Semarang sebagai perguruan tinggi yang berkecimpung dalam pendidikan tenaga kesehatan khususnya bidan, berkewajiban juga untuk menyelenggarakan pengabdian masyarakat guna melaksanakan tri dharma perguruan tinggi. Bentuk pengabdian masyarakat yang diselenggarakan menyesuaikan dengan kegiatan civitas akademika sehari-hari, diantaranya berupa pembentukan kelompok pendamping di Desa Karanggintung Kecamatan Sumbang Kabupaten Banyumas.

Pada bulan juli 2016, gubernur jawa tengah meluncurkan program layanan informasi kesehatan jawa tengah (likes jateng) yang berbasis internet dan dapat diakses masyarakat umum. Salah satu sistem informasi yang berkaitan dengan kesehatan ibu dan anak adalah jateng gayeng nginceng wong meteng (5 NG), yang merangkum segala permasalahan ibu hamil dan bagaimana cara pendekatan yang harus dilakukan agar ibu dan bayinya selamat saat melahirkan. Program 5 NG tersebut memiliki 4 fase, yaitu pra kehamilan, hamil, persalinan dan nifas.

Permasalahan AKI dan AKB merupakan masalah yang serius, sehingga membutuhkan kerjasama semua pihak, tidak hanya akademisi dan praktisi kesehatan, namun juga peran serta masyarakat diantaranya kader PKK di dasawisma. Bahkan pada pelaksanaannya program 5NG akan dikawal dibawah koordinator ketua tim penggerak PKK provinsi jawa tengah. Salah satu outcome yang diharapkan adalah ibu hamil dan masyarakat semakin peduli atas kesehatan ibu dan anak yang pada akhirnya dapat menekan AKI dan AKB. Dengan mengerti dan menyadari faktor resiko tinggi dan faktor tak langsung lainnya, dapat menjaga kesehatan dan keselamatannya, sehingga menjadi masyarakat yang sehat, berpengetahuan, mandiri dan berdikari.

Jika seluruh ibu hamil di suatu wilayah tercatat dengan baik, deteksi dini faktor resiko dan tanda bahaya pada ibu hamil akan lebih mudah teridentifikasi terutama oleh keluarga dan masyarakat sekitar ibu hamil sehingga penyampaian informasi kepada tenaga kesehatan akan lebih cepat dan keterlambatan dalam rujukan kegawatdaruratan dapat lebih ditekan. Upaya tersebut tidak hanya pada masa kehamilan saja, bahkan sampai masa persalinan, nifas dan bayi baru lahir/neonatus. Namun sayangnya di Desa Karanggintung masih ada beberapa ibu hamil yang tidak tercatat, mengingat di desa tersebut banyak berdiri perumahan yang hampir seluruh warganya adalah pendatang dan cenderung memilih periksa kehamilan selain di puskesmas dan bidan desa, sehingga tidak terdata oleh bidan desa. Oleh karenanya pengabdi tertarik untuk membentuk kelompok pendamping ibu hamil di Desa Karanggintung sebagai salah satu upaya meningkatkan pencatatan dan upaya deteksi dini faktor resiko dan tanda bahaya bagi ibu hamil secara terstuktur yang juga sebagai salah satu dukungan terhadap keberhasilan program 5 NG pemerintah provinsi Jawa Tengah.

Tujuan dari kegiatan pengabdian masyarakat ini adalah terbentuk kelompok pendamping ibu hamil di Desa Karanggintung Kecamatan Sumbang Kabupaten Banyumas. Yang mana diharapkan kedepannya dengan adanya kelompok pendamping tersebut dapat meningkatkan pencatatan dan upaya deteksi dini faktor resiko dan tanda bahaya bagi ibu hamil sampai pada masa persalinan, nifas dan BBL / neonatus yang dapat secara terstuktur dilaksanakan oleh pendamping ibu hamil dan bidan, serta kemanfaatannya dapat dirasakan oleh ibu hamil dan keluarganya di Desa Karanggintung.

\section{Metode}

Kegiatan diawali dengan interview terhadap bidan Desa Karanggintung, untuk mengetahui rencana personil yang akan di minta secara sukarela menjadi kelompok pendamping, diperoleh 29 orang sebagai wakil masing-masing RT yang berasal dari kader kesehatan dan kader PKK. Calon kelompok pendamping tersebut diundang untuk mendengarkan pemaparan materi singkat sebagai pengetahuan untuk menjadi kelompok pendamping ibu hamil. Calon pendamping juga dibekali tabel penolong untuk pendamping ibu hamil serta diajarkan cara pengisisannya. Tiga (3) minggu kemudian dilakukan evaluasi pelaksanaan program pada bidan desa dan pendamping tentang bagaimana keberhasilan pengisian tabel penolong, dan adakah kendala yang dihadapi. Untuk evaluasi tahap akhir akan dilaksanakan sesuai saran dari bidan yaitu tri wulan dari pelaksanaan (februari 2018).

Sasaran kegiatan pengabdian ini adalah 
masyarakat DesaKaranggintung khususnya yang berkaitan dengan pemantauan ibu hamil seperti kader kesehatan dan kader PKK yang ditunjuk sebagai kelompok pendamping ibu hamil. Dalam kegiatan pemberian materi untuk calon pendamping turut diundang dukun bayi. Adapun khalayak sasaran secara tidak langsung dari pembetukan kelompok pendamping ibu hamil adalah ibu hamil dan keluarganya di Desa Karanggintung.

Kegiatan pengabdian masyarakat dilaksanakan oleh Dosen dan mahasiswa Prodi DIII Kebidanan Purwokerto sejumlah 9 orang di Desa Karanggintung dengan cara ceramah, diskusi, tanya jawab tentang materi pendampingan ibu hamil, demonstrasi pengisian tabel penolong ibu hamil, evaluasi pelaksanaan sistem pendampingan di lapangan serta pembentukan kelompok pendamping ibu hamil.

Sarana prasarana yang digunakan dalam kegiatan pengabdian masyarakat ini adalah media pembelajaran dan kelengkapan administrasi sebagai kelompok pendamping. Media pembelajaran meliputi power point, booklet materi ringkas bagi kelompok pendamping ibu hamil, lap top dan LCD. Sedangkan kelengkapan administrasi sebagai kelompok pendamping meliputi tabel penolong untuk pendamping ibu hamil, buku KIA, bolpoin dan map plastik.

Adapun pihak-pihak yang terlibat dalam pembentukan kelompok pendamping ibu hamil di Desa Karanggintung Kecamatan Sumbang Kabupaten Banyumas adalah Direktur Poltekkes kemenkes semarang, UPPM Poltekkes Kemenkes Semarang, Ketua Prodi D III Kebidanan Purwokerto, sub UPPM Prodi D III Kebidanan Purwokerto, tiga dosen, satu instruktur, 1 staff dan 5 mahasiswa prodi D III Kebidanan Purwokerto, Kepala Puskesmas I Sumbang, Kepala Desa Karanggintung, Bidan Desa Karanggintung, calon pendamping ibu hamil, Ketua PKK dan dukun di Desa Karanggintung.

\section{Hasil dan pembahasan}

Hasil pelaksanaan kegiatan pengabmas dengan pembentukan kelompok pendamping ibu hamil Desa Karanggintung Kecamatan Sumbang Kabupaten Banyumas pada tahun 2017 ini secara keseluruhan berjalan lancar, namun ada beberapa kendala yaitu pelaksanaan yang tidak sesuai jadwal, 31 \% sasaran sebagai calon kelompok pendamping tidak datang, tabel penolong yang digunakan untuk pendataan oleh kelompok pendamping masih belum sempurna dan mendapatkan masukan dari berbagai pihak, pendamping ibu hamil yang telah melaksanakan pendataan ibu hamil belum 100\% dan yang sudah melakukan pendataan masih ditemui data yang belum lengkap, evaluasi tahap awal tidak $100 \%$ mendapatkan data serta belum bisa dilakukan evaluasi akhir terkait kendala waktu dalam pelaporan.

Sebelum pelaksanaan terlebih dahulu tim melakukan interview dan penjajagan terhadap bidan desa tentang sistem pelaporan adanya ibu hamil di Desa Karanggintung dan siapa saja yang akan ditunjuk untuk menjadi tim pendamping ibu hamil. Bidan menyatakan bahwa dalam pendataan selama ini, jika ada ibu hamil, kader akan melaporkan ke bidan namun belum secara terstruktur (hanya sekedar memberitahu bahwa di wilayah tersebut ada ibu hamil, misal Ny. X). Bahkan ada beberapa RT yang tidak melaporkan ke bidan desa ketika ada ibu hamil di wilayah RT nya. Pada saat tim memaparkan bahwa akan kami coba fasilitasi pembuatan dan penerapan tabel penolong serta penunjukan tim pendamping ibu hamil sebagai upaya peningkatan pencatatan dan upaya deteksi dini faktor resiko dan tanda bahaya ibu hamil sampai masa bersalin, nifas dan BBL/neonatus, bidan desa sangat mendukung. Sedangkan tim yang akan di ajukan sebagai kelompok pendamping ditunjuk satu orang di masing-masing RT di Desa Karanggintung, sejumlah 29 RT berasal dari kader kesehatan dan anggota PKK.

Pada tanggal 3 November 2017 masing-masing calon pendamping ibu hamil diundang ke balai desa utuk mendengarkan pemaparan materi ringkas untuk menjadi pendamping ibu hamil beserta demonstrasi cara pengisian tabel penolong pendamping ibu hamil, yang akan diisi data-data ibu hamil di wilayah RT masing-masing dan dikuti perkembangannya sampai masa bersalin, nifas dan BBL/neonatus. Materi ringkas yang disampaikan meliputi jadwal kunjungan, faktor resiko dan tanda bahaya pada ibu hamil, bersalin, nifas dan BBL/neonatus. Dari 29 calon pendamping di desa Karanggintung yang diundang, 9 diantaranya tidak dapat hadir (31\%).

Sejak awal pertemuan Tim pengabmas telah menyampaikan bahwa, menjadi pendamping ibu hamil menerapkan asas kesukarelaan, tidak mengharapkan imbalan apapun. Hal tersebut disambut positif oleh calon pendamping ibu hamil, dan mereka bersedia untuk berkomitmen menjadi pendamping ibu hamil di Desa Karanggintung. Tim pengabmas juga menyampaikan bahwa pendataan oleh tim 
pendamping merupakan suatu langkah awal, verifikasi kebenaran data akan dilakukan oleh bidan ketika ibu hamil periksa ke bidan. Sedangkan bagi ibu hamil yang periksa ditempat lain, data tersebut juga memiliki manfaat yaitu bidan tetap memiliki data awal, termasuk faktor resiko yang dimiliki walaupun ibu hamil tidak periksa ke bidan desa.

Pada saat pemaparan materi, turut hadir pula ketua penggerak PKK di Desa Karanggintung beserta dukun bayi. Tamu undangan terlihat cukup antusias dengan program yang akan di laksanakan, terbukti dengan adanya pertanyaan-pertanyaan terkait pelaksanaan program pendampingan ini di Desa Karanggintung kedepannya. Pertanyaan tersebut meliputi bagaimana pendamping ibu hamil bisa melakukan pendekatan terhadap ibu hamil dan keluarga yang agak sulit, bagaimana alur rujukan jika menemui tanda bahaya selama masa hamil bersalin nifas ataupun bayi baru lahir, menanyakan beberapa permasalahan kesehatan di masyarakat terkait dengan budaya dan kesehatan ibu hamil dan bagaimana sistem pelaporan ketika pendampingan ibu hamil telah berjalan. Tim pengabmas mencoba menjawab pertanyaan-pertanyaan tersebut dibantu oleh bidan desa selaku pemilik wilayah. Direncanakan pelaporan ke bidan dari pendamping ibu hamil pada setiap kegiatan perkumpulan kader atau pada saat program ibu hamil seperti kelas ibu hamil.

Evaluasi awal dilaksanakan pada minggu ke 4 bulan November atau 3 minggu setelah pemberian materi di balai desa. Tim berkeliling ke 11 pendamping dan ke bidan desa, namun tidak semuanya memberikan hasil. Beberapa pendamping sudah selesai melakukan pendataan dengan lengkap, namun ada pula yang belum mendapatkan data dengan alasan di RT tersebut tidak ada ibu hamilnya, pendamping belum melakukan pendataan, ibu hamilnya sedang pindah domisili sementara sehingga belum bisa di data, pendamping belum menerima seperangkat kelengkapan adminsitrasi pendataan ibu hamil karena pada saat acara di balai desa tidak hadir dan ada pula yang ketika di datangi tim pengabmas beliau tidak berada di tempat sehingga tim menghubunginya lewat handpone. Bidan desa memberikan pernyataan yang sama, bahwa sebagian pendamping telah mengisi tabel penolong dengan benar dan dilaporkan ke bidan ketika pelaksanaan kelas ibu hamil. Permasalahan yang ditemukan selama evaluasi di lapangan oleh tim pengabmas di laporkan kepada bidan desa, untuk selanjutnya ditindak lanjuti dalam rangka membangun sistem kerja kelompok pendamping ibu hamil di Desa Karanggintung lebih optimal.

Terkait dengan data pada tabel penolong yang diisi oleh kelompok pendamping, bidan desa menyampaikan beberapa hal yang perlu di tambahkan ke dalam tabel tersebut yaitu data umur ibu (tempat tanggal lahir) dan data jaminan kesehatan yang dimiliki. Masukan juga di sampaikan oleh tim UPPM dari Poltekkes Kemenkes Semarang, terkait beberapa perbaikan dalam tabel penolong, yaitu penambahan data jaminan kesehatan yang dimiliki, menyederhanakan bahasa dalam lembar penjelasan, menyederhanakan pengisian untuk faktor resiko dan tanda bahaya dengan cukup melingkari atau melakukan cheklist pilihan yang sesuai sehingga tidak perlu menulis. Ada pula masukan terkait dengan proses pelatihan yaitu melaksanakan pre-test dan post-test untuk mengetahui tingkat pengetahuan pendamping sebelum dan sesudah di berikan materi sebagai calon pendamping ibu hamil.

Secara umum pendamping tidak mengalami kesulitan ketika mengisi tabel penolong atau melakukan pendataan ibu hamil, karena bahasa yang tercantum dalam tabel penolong dinilai cukup mudah untuk dipahami. Namun, ada beberapa item yang belum diisi dengan lengkap seperti HPHT, jumlah persalinan, keguguran dan anak hidup. Untuk faktor resiko ibu hamil sebagian besar tidak ada, namun ada juga yang menemukan faktor resiko yaitu usia ibu > 35 tahun. Beberapa ibu hamil yang sudah berhasil didata menunjukkan bahwa sudah melakukan kunjungan hamil rutin, bahkan ada yang sudah melebihi 4 kali, namun ada pula yang sudah berusia 7 dan 5 bulan baru periksa kehamilan 1 kali, dan tidak ada catatan pemeriksaan pada saat kehamilan trimester I.

Evaluasi tahap akhir untuk menilai berjalannya sistem secara keseluruhan dan kemanfaatan dari hadirnya kelompok pendamping belum dapat dinilai, mengingat jangka waktu yang pendek dari pemberian materi. Evaluasi tahap akhir tersebut direncanakan akan dilaksanakan tiga bulan dari pemaparan materi sebagai pendamping ibu hamil, mengikuti jadwal pertemuan kader pada bulan tersebut.

Sebuah artikel di web Dinas Kesehatan Provinsi Jateng menuliskan bahwa PKK, dasa wisma dan masyarakat dapat berperan aktif memantau, mengingatkan, mengarahkan bahkan memfasilitasi untuk melakukan pemeriksaan 
secara rutin. Hal ini telah sesuai dengan pelaksanaan pembentukan kelompok pendamping di Desa Karanggintung, terbukti dengan mengikutsertakan beberapa anggota PKK sebagai calon pendamping ibu hamil bahkan ketua penggerak PKK hadir langsung dan memberikan dukungan dalam program tersebut. Pembentukan kelompok pendamping ini merupakan salah satu upaya kesehatan yang menerapkan sistem pemberdayaan masyarakat. Masyarakat dalam hal ini adalah kelompok pendamping, merupakan salah satu orang yang berada di sekitar ibu hamil di wilayah RT masing-masing. Yang mana pendamping ibu hamil lebih memungkinkan untuk mengetahui lebih awal jika terjadi tanda bahaya ataupun kegawatdaruratan pada ibu hamil tersebut, sehingga rujukan dapat dilakukan lebih dini.

Artikel dari Web Dinas Kesehatan Provinsi Jateng tersebut juga menyatakan bahwa Pendataan ibu hamil mencakup jumlah ibu hamil, HPL, NIK, domisili dimana, dan apa saja faktor resikonya. Namun, pada pelaksanaanya ada beberapa hasil pendataan pendamping ibu hamil yang belum dapat mengkaji hari pertama haid terakhir (HPHT), dimana HPHT tersebut diganakan untuk menghitung HPL.

Hasil pendataan yang dilakukan salah satu pendamping, mendapatkan hasil bahwa ada ibu hamil yang usia kehamilan sudah menginjak 5 dan 7 bulan, namun baru satu kali periksa kehamilan di trimester 2, sehingga trimester 1 ibu hamil tersebut sama sekali tidak melakukan pemeriksaan kehamilan. Hal ini tidak sesuai dengan yang tercantum dalam buku KIA (2016) bahwa jika wanita terlambat datang bulan, segera ke dokter atau bidan untuk periksa kehamilan minimal 4 kali selama kehamilan, 1 kali pada usia kandungan sebelum 3 bulan, 1 kali usia kandungan 4-6 bulan dan 2 kali pada usia kandungan 7-9 bulan. Tim sekaligus meminta pendamping untuk memotivasi ibu hamil rutin control atau periksa kehamilan.

Salah satu faktor resiko ibu hamil adalah Primigravida $<20$ tahun, atau $>35$ tahun. Di lahan faktor resiko umur ditemukan, yaitu ibu hamil dengan usia 42 tahun. Walaupun ibu tersebut bukan primigravida (sudah hamil ke empat) akan tetapi hal tersebut tetaplah menjadi faktor resiko yang perlu diwaspadai. Hal ini menjadi bukti bahwa pendataan oleh kelompok pendamping dapat mendeteksi faktor resiko ibu hamil, sehingga selama kehamilan dan persalinan harus dikawal dengan lebih intensif.

Beberapa permasalahan yang ditemukan tim pengabdi selama proses evaluasi di lapangan terkait teknis pelaksanaan di lapangan telah dilaporkan kepada bidan desa, untuk dapat ditindaklanjuti. Sedangkan permasalahan terkait dengan kelengkapan yang ada dalam tabel penolong akan diperbaiki oleh tim pengabdi. Harapan kedepannya pada saat evaluasi tahap akhir, sistem telah terbentuk dengan baik dan dapat diajukan SK kepala desa tentang kelompok pendamping ibu hamil di Desa Karanggintung. Besar harapan agar kelompok pendamping tersebut dapat benar-benar melaksanakan fungsinya melakukan pendampingan pada ibu hamil dari masa hamil, bersalin sampai nifas bahkan termasuk pendampingan pada bayi baru lahir atau neonatus.

\section{Kesimpulan dan saran}

Kesimpulan dari hasil kegiatan pengabdian masyarakat dengan judul pembentukan kelompok pendamping ibu hamil di Desa Karanggintung Kecamatan Sumbang Kabupaten Banyumas ini meliputi: (1) telah terbentuk kelompok pendamping di Desa Karanggintung di 29 RT dengan masing-masing 1 orang pendamping. Kelompok pendamping telah berkomitmen untuk melaksanakan fungsinya sebagai pendamping ibu hamil mulai dari masa hamil, bersalin, nifas dan BBL/ neonates; (2) Pendataan awal oleh kelompok pendamping telah mampu mendeteksi salah satu faktor resiko ibu hamil, yaitu usia $>35$ tahun, (3) Kendala yang dihadapi selama kegiatan pengabdian adalah pelaksanaan yang tidak sesuai jadwal, 31 \% sasaran sebagai calon kelompok pendamping tidak datang saat pelatihan, tabel penolong yang digunakan untuk pendataan oleh kelompok pendamping masih membutuhkan perbaikan, pendamping ibu hamil yang telah melaksankan pendataan ibu hamil belum $100 \%$ dan yang sudah melakukan pendataan masih ditemui data yang belum lengkap, evaluasi tahap awal tidak $100 \%$ mendapatkan data serta belum bisa dilakukan evaluasi akhir terkait kendala waktu dalam pelaporan dan (4) Bersama bidan desa perbaikan sistem dalam menjalankan program kelompok pendamping ibu hamil akan terus ditingkatkan dan akan diajukan sebagai SK kepala desa tentang kelompok pendamping ibu hamil

Saran yang dapat disampaikan pada laporan pengabdian masyarakat ini meliputi : (1) Bagi bidan desa adalah peran aktif dalam mengkoordinasi kelompok pendamping sangat dibutuhkan, demi keberhasilan pembentukan dan pelaksanaan fungsi dari kelompok 
pendamping; (2) Bagi kelompok pendamping adalah diminta untuk menjaga komitmen untuk menjalankan fungsinya sebagai pendamping ibu hamil sampai ibu bersalin dan melewati masa nifasnya dan (3) Bagi tim pengabdi adalah agar dapat mengembangkan sistem yang serupa atau bahkan lebih baik lagi dalam kegiatan pengabmas berikutnya.

\section{Ucapan terimakasih}

Ucapan terimakasih kami sampaikan kepada Poltekkes Kemenkes Semarang yang telah mendanai kegiatan pengabdian masyarakat ini. Ucapan terimakasih juga kami sampaikan kepada semua pihak yang terkait dengan pelaksanaan kegiatan pengabdian masyarakat.

\section{Daftar pustaka}

Kemenkes. 2016. Buku Kesehatan Ibu dan Anak. Jakarta: Kemenkes dan JICA

Dinkes Prov Jateng. Upaya Penurunan AKI Melalui Program KKBPK. Semarang: disampaikan dalam rapat koordinasi daerah (rakorda) KB

Dinkes Prov Jateng. Selamatkan Ibu dan Anak melalui program 5 NG. www.dinkesjatengprov.go.id. Diakses 13 Juli 2017

Dinkes Prov Jateng. LIKES Jateng Resmi Diluncurkan. www.dinkesjatengprov.go.id. Diakses 13 Juli 2017 